\title{
Supply Chains in the Apparel Industry: Do Transnational Initiatives for Social Sustainability Improve Workers' Situation?
}

\section{Claude Meier}

HWZ University of Applied Sciences in Business Administration Zurich, Switzerland

Non-state driven Transnational Initiatives for Social Sustainability (TISSs) have increasingly attempted to approach social issues like labour laws in global supply chains. The reason is that state-laws are territorially confined. But can TISSs contribute to effective solutions of issues on which they are focused? This examination presents a theoretical framework explaining the effectiveness of TISSs. For the empirical case study, the Business Social Compliance Initiative (BSCl) and the Fair Wear Foundation (FWF) were selected. Data was collected from expert interviews and documents. The results led to the conclusion that stakeholder-involving approaches are adequate to support social sustainability in the future.

Keywords: transnational initiatives, globalisation, social sustainability, apparel industry, stakeholder, labour rights

\section{Introduction}

In today's globalised world, supply chains have become transboundary: products are often designed in one part of the world and produced in another. Because there are no state-based mandatory laws on the global level, issues linked to transboundary supply chains like labour rights are, in fact, usually unregulated (which can lead, e.g., to unacceptable labour conditions) (Dingwerth \& Pattberg, 2006; Rosenau \& Czempiel, 1992; Willke, 2014). In the last 15 years, voluntary transnational initiatives that aim to contribute to social or environmental sustainability have increasingly attempted to fill this regulatory gap (Fransen, 2012; Levy \& Kaplan, 2008). Over a decade after the demand for and establishment of transnational initiatives for social sustainability (TISSs), the central question is if and how effectively they reach their own aims (e.g., implementation of labour rights) (Abbott \& Snidal, 2009; Fransen, 2012; Held, 2004; Rieth, 2009; Van Tulder \& Kolk, 2001; Zadek, 2004).

This study, therefore, examines what rules influence the effectiveness of achieving the self-declared aims of TISSs. This is of importance because 
social sustainability is only provided if TISSs contribute effectively to the achievement of self-declared aims. This is also important for companies that implement TISS's rules, as it affects the credibility of their corporate social responsibility (CSR) concepts.

As cases, the two TISSs Business Social Compliance Initiative (BSCl) and Fair Wear Foundation were selected (for more information on the cases, see methodology section). They are both focused on the apparel industry and aim to provide labour conditions for workers in production places that are accordant with core conventions of the International Labour Organisation (ILO). The provision of such conditions can be understood as social sustainability. The abstract of this paper has been presented and published at the MakeLearn \& TIIM 2015 International Conference. The content presented in the article is part of a broader study on the effectiveness of TISSs (Author).

\section{Theoretical Framework}

Generally, the basis of a TISS is its formal rules. The different rules have a potential to influence the effectiveness of a TISS. Effectiveness means the extent to which a TISS has achieved conformity in practice with its own aims as stated in its set of rules. In the following three theoretically central effectiveness-influencing rules (rules to support provision of information, rules for multi-stakeholder dialogues and rules for involvement of the stakeholder member-company) are explained, because they are influential, they are taken as independent variables while effectiveness, which is influenced by these rules, is taken as the dependent variable (for more details, see section research design).

\section{Rules to Support Provision of Information}

The first two rules to be considered are audit systems and transparency requirements. According to the stakeholder agency theory, both audit systems and transparency are part of those rules supporting the provision of information about an agent's activities (Hill \& Jones, 1992; Shankman, 1999). The concept of agency theory is that a principal that has a stake concerning a certain issue delegates tasks by referring this issue to an agent (Fama, 1980; Fama \& Jensen, 1983; Hill \& Jones, 1992; Jensen \& Meckling, 1976). In the case of the BSCI and FWF, this means that these two TISSs are the principals that have a stake with regard to the social issue labour rights in global supply chains. Companies in the apparel industry that became members of BSCl or FWF have committed themselves to implement these TISSs' rules. Therefore, these member-companies are understood as the agents that act on behalf of or according to the rules of either BSCI or FWF. The management of a member-company thereby never 
has exactly the same interests as the TISS: providing social sustainability is rarely the primary interest of a company (Rondinelli, 2002). Thus there is, at least to a certain extent, a divergence of interests between the company and TISSs. Moreover, while the company, as an agent, knows its activities, the TISS as a principal has less information about these activities. This leads to information asymmetry. The audit systems and transparency requirements are rules that intend to transfer relevant information from the member-company to BSCl or FWF with the aim to align their interests. This theoretical consideration leads to the following thesis:

T1 Audit systems (a) and transparency requirements (b) provide TISSs with relevant information and thus help to lower the information asymmetry between a TISS (principal) and a member-company (agent). This is assumed to support the alignment of interests between these two actors and to accordingly increase the effectiveness of TISSs.

\section{Multi-Stakeholder Dialogues}

The literature states that multi-stakeholder dialogues contribute to solutions of issues like labour laws by supporting an interactive process (Calton \& Payne, 2003; Mena et al., 2010; Strand, 2010). Such dialogues are characterised by a plurality of views regarding the central issue: Fact-perceptions and values are integrated and reconstructed in them. Multi-stakeholder dialogues around an issue can be initiated and integrated into the rules by a TISS (and thus also by $\mathrm{BSCl}$ and FWF). The iterated interactions between stakeholders in dialogues are assumed to lead to a more convergent understanding of the issue and in a next step lead to a process of learning (Calton \& Payne, 2003). Converging understanding and collective learning are thus conditions to contribute effectively to solutions regarding an issue (Camillus, 2008). This leads to the following thesis:

T2 Multi-Stakeholder dialogues that lead to a more convergent understanding of an issue and to a collective learning process are assumed to help to contribute to solutions regarding the issue and to accordingly increase the effectiveness of TISSs.

\section{Involvement of the Stakeholder Member-Company}

The next aspect considered is the involvement of the TISS member-company as required by rules. It is assumed that by incorporating the rules of the TISS and their underlying meaning into the management system of a member-company, a TISS' potential to contribute effectively to solutions of the focused issue is increased (Abbott \& Snidal, 2009; Delmas, 2001). This is strongly supported if central responsibilities concerning ruleimplementation on an operational level are also explicitly transferred to a 
member-company. If both of these aspects are required, the rules of a TISS become deeply incorporated in a company's organisation (if done seriously). During the process of incorporating and implementing the rules, the company can develop its knowledge in social sustainability (Sachs \& Rühli, 2011). Knowledge is not only a central resource when effectively implementing social sustainability, it is also a principally unlimited resource. Therefore knowledge has the potential to be increased when the company cooperates (e.g., in networks) with external stakeholders (Sachs \& Rühli, 2011). In other words, when the resources of knowledge from different stakeholders are bundled in an aim-oriented way through cooperation, core competencies can be established. Such core competencies go beyond what any single company can do (Prahalad \& Hamel, 1990; Sachs \& Rühli, 2011). This leads to the following thesis:

T3 A strong involvement of the member-company required by the rules of the TISS (with regard to management systems and implementation on an operational level) is assumed to foster the development of issueoriented knowledge and thus to contribute to solutions regarding the issue and to accordingly increase the effectiveness of the TISSs.

\section{Methodology}

\section{Research Design}

The examination was conducted by means of a case study. More precisely, an elementary cross-case comparison oriented at John Stuart Mill's method of difference (George \& Bennett, 2005; Lijphart, 1971) was performed. This method 'attempts to identify independent variables associated with different outcomes [of the dependent variable]' (George \& Bennett, 2005, p. 153). To do so the selected cases have to be similar concerning as many aspects as possible, but have to differ concerning a few central aspects (i.e., independent variables) that influence the dependent variable according to their values (Przeworski \& Teune, 1970). Following this, independent variables that have a covariance with the dependent variable should be identified. Because the outcome of the dependent variable was unknown ex-ante, I first theoretically derived plausible independent variables that had a potential covariance with the dependent variable. These were, as indicated in the theoretical section, the three explained effectiveness-influencing rules: rules to support provision of information, for multi-stakeholder dialogues and for involvement of the stakeholder member-company. The dependent variable is effectiveness (as also indicated in the theoretical section).

A discussion and conclusion about the plausibility of the theoretical theses (T1-T3, see theoretical section) that connect the independent to the dependent variables was then conducted on the basis of the empirical data. 
Independent Variables

Rules to Support Provision of Information

Rules for Multi-Stakeholder Dialogues

Rules for Involvement of the Stakeholder Member-Company
Dependent Variable

Effectiveness (achievement of conformity with the aims of the selected TISS)

Figure 1 Variables

Case studies as a method for small-n examinations are appropriate to conduct this study because they are strong 'at assessing whether and how a variable mattered to the outcome of the [dependent variable]' (George \& Bennett, 2005, p. 25). They are, however, weak in assessing how much an independent variable mattered (George \& Bennett, 2005). This leads to the following framework:

\section{Case Selection}

As previously mentioned, the TISSs Business Social Compliance Initiative (BSCl), a business-driven initiative, and Fair Wear Foundation (FWF), a civil society-driven initiative, were selected as cases. The primary reason for their selection is that they enable a cross-case comparison according to the method of difference (see last section). Among the most important similarities between BSCI and FWF are that they both cover the apparel industry (which was chosen because TISSs have existed in this industry for over a decade) and that they have similar objectives: both TISSs require the central core-conventions of the ILO to be accomplished and maintained in their member-companies' production places, both are common in European countries and members are brands or retail companies that are based there. However, they differ with regard to some theoretically central rules like their requirements concerning the involvement of the TISS member-companies, especially on the implementation level, as well as their approaches towards transparency (BSCI, 2009a, 2009e, 2012; FWF, 2009a, 2012a). What both TISSs have, though, are audit systems. Moreover, case studies are appropriate when a small number of cases are investigated (small-n investigation).

\section{Data and Measurement}

As data sources for the dependent variable (effectiveness), audit reports from BSCl and FWF were used. These audit reports are confidential, i.e., not publicly accessible, and provide information about the social performance of TISS-relevant ILO core-conventions in production places. In the case of FWF, 
the reports were provided by FWF itself. A systemic data archive was not established by FWF at the time of the request, that is why it was not possible to follow a fully systematic selection process. In the case of $\mathrm{BSCl}$, access to audit reports was first allowed but later refused when they realised that FWF was also a case in the study. Nevertheless, a Swiss member-company directly provided their audit reports for the study.

The audit reports show an achieved level of conformity with aims (= effectiveness) or a 'reached state' at certain points in time. To identify and 'measure' changes in levels of conformity over time, the audit reports were selected and arranged in a longitudinal manner: two or more timely successive audit reports from a TISS referring to one single production place are considered to be a package (George \& Bennett, 2005). The older and the newer audit reports of a factory were compared to each other with regard to conformity with ILO core-conventions. The ILO core-conventions, declared as aims to be achieved by both the $\mathrm{BSCl}$ and $\mathrm{FWF}$, served as standards of reference and were, after being sorted into categories, considered in the examination (see table 1) (BSCI, 2009a; FWF, 2009a; ILO, 2012; Miles et al., 2002). If the newer audit report in a package included a reached state that is closer to conformity than the older report, this implies a change in conformity-level towards improvement in labour rights and in social sustainability, respectively.

For the different levels of conformity, a scoring system with three values was established: 1 = not conform, 2 = partly conform, 3 = conform. 27 FWF audit reports (13 packages) and $8 \mathrm{BSCl}$ audit reports (4 packages) comprise the data bases (Mayring, 2010; Miles et al., 2002). To avoid a country bias (i.e., to hold the national context constant), audit reports were taken exclusively from production places in China (Rieth, 2009). To assess conformity in the reports, the qualitative data software atlas.ti was used (Friese, 2012). Atlas.ti was suitable for transforming the qualitative data into numeric data on the ordinal scale described (i.e. from $1=$ not conform to 3 = conform).

If an improvement occurred, the question arose of whether it was indeed linked to the TISS' rules (independent variables). Moreover, although audit reports are probably the most standardised data source to assess effectiveness, the single reports sometimes varied a great deal concerning the quality of the content: sometimes the audit-template contained only very short comments while others had detailed sentences. Furthermore, it is not ensured that a subsequent audit report made reference to objections stated in the preceding report. And last but not least, for $\mathrm{BSCl}$ there are only 4 audit report packages with data from one company. Overall, these and other weaknesses and their effects on validity have been minimised as far as possible by considering them in the system of analysis. 
Table 1 Considered ILO Core-Conventions

\begin{tabular}{ll}
\hline Category & ILO core-convention \\
\hline Working Hours & C1 - Hours of Work (Industry) Convention 1919 \\
Wages & C26 - Minimum Wage-Fixing Machinery Convention, 1928 \\
& C131 - Minimum Wage Fixing Convention, 1970 \\
\hline Freedom of & C87 - Freedom of Association and Protection of the Right to Organise \\
Association (FoA), & Convention, 1948 \\
Right to Collective & C98 - Right to Organise and Collective Bargaining Convention, 1949 \\
Bargaining (RCB) & C135 - Workers' Representatives Convention, 1971 \\
\hline Employment is & C29 - Forced Labour Convention, 1930 \\
freely chosen & C105 - Abolition of Forced Labour Convention, 1957 \\
\hline Discrimination & C100 - Equal Remuneration Convention, 1951 \\
& C111 - Discrimination (Employment and Occupation) Convention, \\
& 1958 \\
\hline Child Labour & C138 - Minimum Age Convention, 1973 \\
\hline Health and Safety & C155 - Occupational Safety and Health Convention, 1981 \\
\hline
\end{tabular}

For assessing the independent variables (rules to provide information, stakeholder dialogue, involvement of the TISS member-companies), the central rule documents of $\mathrm{BSCl}$ and FWF were taken (BSCl, 2009a, 2009b, 2009c, 2009d, 2009e, 2009f; FWF, 2009a, 2009b, 2010, 2012b, 2012c). These documents contain TISS' aims, intentions and implementation procedures. Among others, the ILO core-conventions with which a membercompany has to comply are also mentioned within these documents.

As a data source these rule documents were generally valid: overall, the relevant contents were comprehensively available and they were basically comparable.

To serve as a third data source, expert interviews (Gläser \& Laudel, 2010) were conducted with experts of BSCl and FWF, with supply chain officers and persons responsible for social sustainability in member-companies as well as with responsible persons in production places (factories) in China (Guangdong and Shanghai). Moreover, interviews were held with experts from NGOs in Switzerland and Hong Kong. Overall, 17 interviews of approximately one hour were conducted. The guideline for the semi-structured interviews was derived from theoretical considerations. The analysis was done by a qualitative content analysis. The qualitative data analysis software atlas.ti was used for interviews (Friese, 2012; Gibbs, 2007; Gläser \& Laudel, 2010; Mayring, 2010). Interviews are not tied to a specific variable. Their purpose is to offer a clearer empirical link between the two variables by providing more detail and context information.

The weakness of interviews is that no direct observation is possible: interviewees can react to the asked questions however they want (bias be- 
Table 2 Improvements and average scores

\begin{tabular}{lcrrrr}
\hline & \multicolumn{2}{c}{ FWF } & & \multicolumn{2}{c}{ BSCI } \\
\cline { 2 - 3 } \cline { 6 - 6 } Category & $(1)$ & $(2)$ & & $(1)$ & $(2)$ \\
\hline Employment is freely chosen & $16.4 \%$ & 2.91 & & $0.0 \%$ & $*$ \\
Discrimination & $23.5 \%$ & 2.97 & & $33.3 \%$ & 2.30 \\
Child labour & $32.3 \%$ & 2.55 & $33.3 \%$ & 2.50 \\
FoA and RCB & $28.6 \%$ & 1.93 & & $9.1 \%$ & 1.80 \\
Wages & $32.8 \%$ & 2.44 & $26.0 \%$ & 1.83 \\
Working hours & $26.2 \%$ & 1.66 & & $50.0 \%$ & 2.29 \\
Health and safety & $17.0 \%$ & 2.50 & $10.8 \%$ & 2.62 \\
\hline
\end{tabular}

Notes Column headings are as follows: (1) ratio of improvements, (2) score of category. $*$ No specification in any report.

cause of reactivity) (Gläser \& Laudel, 2010). Moreover, there is no full standardisation: interviewees differ in their eloquence and astuteness. Interinterviewer reliability was assured in this study because all interviews were conducted exclusively by one person. Furthermore, high validity was ensured by methodological selection criteria for interviewees (experts from companies vs. NGOs, Europe vs. Asia) and by applying the same interview guideline for all interviewees.

\section{Findings}

In table 2, improvements and average scores per ILO core-convention category are shown for FWF and $\mathrm{BSCl}$ (on the basis of audit report packages). The ratio of improvements shows the amount of improvements that effectively took place divided by the amount of potentially possible improvements.

In the following pages, the findings are presented and discussed along the three theses postulated in the theoretical section (T1-T3). Note that the scores on wages and working hours are of low reliability because of many inconsistencies in the data sources and also in the audit reports themselves. Inconsistencies range from inaccuracies (e.g., manual or no time record system, too early/late stamp) to intentional falsification.

\section{Rules to Support Provision of Information: Audit System (T1a)}

As mentioned previously, BSCl and FWF both have audit systems: professional audit teams check conformity with the relevant categories of ILO coreconventions. The sources of information of audits are, in both cases, interviews with management and workers, as well as the review of documents and work place inspections. After an audit, $\mathrm{BSCl}$ and FWF established corrective action plans that would then be discussed with the management of a production place. 
The table 2 shows that improvements towards conformity in both cases indeed took place in different categories of ILO core-conventions. Interviewees stated that audits primarily lead to changes in behaviour in categories that are easy to measure, such as health and safety. Generally, this is consistent with findings in audit reports (dependent variable): They show higher scores in categories that are assumed to be easier to measure, e.g., health and safety, child labour and, to a lesser extent (concerning measurability), if employment is freely chosen (i.e., not forced labour).

Overall, the theoretical consideration that audit systems help to lower information asymmetry between the TISS (principal) and member-company (agent) and that this supports the alignment of interests between these two actors seems basically plausible. The potential for information transfer is, however, limited concerning categories of labour issues that are more difficult to assess (e.g., FoA and RCB). What contradicts this conclusion is that the improvement-ratios of difficult-to-measure categories are often quite high. Overall, the manipulability of audit reports mentioned in interviews has to be taken into consideration. Many interviewees stated that audits alone are not enough to achieve conformity with labour rights.

\section{Rules to Support Provision of Information: Transparency (T1b)}

In contrast to $\mathrm{BSCl}$, FWF requires its members to publish a social report on their homepage as well as on FWF's. BSCl members are required to communicate their membership but not to publish any social reports. Interviewees frequently stated (from NGOs, member-companies to factories and TISS experts) that the pressure to publish has a positive influence on the implementation of ILO core-conventions. The requirement to publish information about social performance like labour issues put internal pressure on responsible persons to really implement the TISS' rules. Seen from this vantage point, the requirement of transparency towards all stakeholders can be understood as a rule that lowers the information asymmetry between the TISS and member-company. Thus, the pressure to publish indeed supports the alignment of interests between the two actors and accordingly facilitates an effective implementation of ILO core-conventions.

A link to the findings in audit report-packages may be detected in the clearly higher overall-improvement ratio of FWF (29.7\%) than $\mathrm{BSCl}(21.7 \%)$ and the higher score (FWF 2.3, BSCl 2.0). This, of course, is only an indication and it is not clear if this connection is causal. For a more accurate and reliable conclusion, more data, especially from $\mathrm{BSCl}$, would be needed.

\section{Stakeholder dialogue (T2)}

With regard to stakeholder dialogue, BSCI and FWF have similar platforms to involve issue-relevant stakeholders in discussions. The most important 
ones are stakeholder meetings on national and international levels as well as round tables for stakeholder dialogues in production countries (in both companies, NGOs and sometimes State actors participate). Most interviewees from member-companies and Western NGOs find stakeholder meetings to be useful because they support the comprehension of views of other stakeholder. According to interviewees, in this way it is indeed possible to come to a more convergent understanding of the issues. Moreover, practical implementation approaches are discussed among the experts from different stakeholder groups.

Overall, stakeholder dialogue seems to support the technical exchange and the understanding between stakeholder groups and of issues. This fosters and can be seen as sustainable collective learning. Therefore, overall, it is plausible to assume that stakeholder dialogues support an effective implementation of ILO core-conventions. This finding is limited by the fact that an immediate causal effect of stakeholder dialogues on audit reportpackages could not be ascertained based on the available data.

\section{Involvement of TISS Member-Companies (T3)}

According to their rules, FWF requires a stronger involvement from its member-companies than BSCl. Members of FWF have to adapt their management system and to establish systems to monitor the implementation of ILO core-conventions in production places. All of this is checked by FWF, but the main responsibility is in the hands of FWF member-companies. BSCl, which does not have such requirements, provides its members with recommendations on how to adapt management systems for social sustainability in labour rights.

Interviewees largely stated that the involvement of member-companies is an important aspect of the implementation of a TISS' requirements concerning labour rights. It was also stated that an effective implementation depends on the input of resources. The level of the input depends on the will of a member-company. To decrease the need of high resource input and to use synergies, the cooperation between competing membercompanies was mentioned (e.g., by enhancing market power: competing member-companies often buy from the same suppliers).

Through such cooperation with suppliers and competitors, the knowledge pool as the resource for establishing potential core competencies with regard to social sustainability towards labour rights increases. Thus, close cooperation of a member-company with its suppliers allows them to establish and develop core competencies concerning labour rights. These competencies can be expanded to inter-company core competencies through cooperation and learning towards labour rights between member-companies. Based on interview data, the assumption that a strong involvement of member- 
companies supports an effective implementation of ILO core-conventions is plausible. A direct relationship to improvements in audit report-packages cannot, however, be ascertained.

\section{Assessing causality}

Based on the available data, it was generally not possible to find causal proof to determine if TISSs are indeed responsible for detected improvements in empirics. Therefore, a method which I call 'causality check' was applied to audit report packages (see section data measurement). This check looks for text-based causalities: if there are clear implicit or explicit statements in the second audit reports that refer to objections stated in the first audit reports, then causality is assumed to be present (of course, this primarily considers the thesis of audit (T1) systems because the bases are exclusively audits and audit reports). In sum, a total of $23.81 \%$ of all improvements by $\mathrm{BSCl}$ and FWF can be assumed to be of a causal nature. In around two thirds of all improvements cases, it is not implausible to assume causality. And in about $10 \%$, information was too sparse to assess causality or there were clearly other reasons for improvements.

The category of FoA and RCB was particularly noteworthy. During analysis (and not before) it was detected that $\mathrm{BSCl}$ does not insist on all its own specific requirements to be implemented in China. FWF, on the other hand, does require it. These results are striking: the improvement ratio of FWF (28.6\%) is much higher than that of $\mathrm{BSCl}(9.1 \%)$. This points to a considerable effectiveness of TISSs (here of FWF).

\section{Conclusion}

The examination showed that improvements concerning social sustainability in labour rights in production places of global supply chains can indeed be achieved. If and how these improvements are linked causally to TISSs in detail could, however, not be made fully clear based on the available data (especially for $\mathrm{BSCl}$, as there are only audit reports from one company). Nevertheless, the data from the interviews overall supports the plausibility of the theses that audit systems (T1a), transparency (T1b), stakeholder dialogues (T2) and a stronger involvement of the TISS member-companies (T3) facilitate increasing labour conditions (as well as the special case of FoA and RCB as explained in the last section). Moreover, the findings show that audit systems mainly support improvements in categories that are easy to assess, but not in those that are more difficult to measure. Thus, audit systems are not enough. This is probably because audit systems neither foster deeper interactions between stakeholders nor a collective inter-stakeholder learning. They merely control conformity with ILO core-conventions. This is different concerning stakeholder dialogue and in- 
volvement of the TISS member-companies. With these rules (as especially stated in interviews) interactions between stakeholders are fostered: this results in a better comprehension of the issues between the different stakeholder groups and leads to a more convergent understanding. The considered forms of stakeholder involvement led to the establishment and development of knowledge in the field of labour issues and to inter-company as well as to inter-stakeholder core competencies. Knowledge as the basic resource for collective learning is thus established by organised stakeholder involvement or as required by the TISS.

In future research, the specific mechanisms of stakeholder involvement could be investigated because institutionalised interaction between stakeholders seems to be essential for labour issues that are difficult to assess. Conceptually, it would also be meaningful to examine single categories of labour issues in more depth with the aim to understand the causal mechanisms more accurately. Of course, adequate data would be needed for this. For the ascertainment of statistical causality, quantitative examinations could be undertaken, provided the necessary data can be collected.

\section{References}

Abbott, K. W., \& Snidal, D. (2009). The governance triangle: Regulatory standards institutions and the shadow of the state. In W. Mattli \& N. Woods (Eds.), The politics of global regulation (pp. 44-88). Princeton, NJ: Princeton University Press.

BSCl. (2009a). Code of conduct. Retrived from http://www.bsci-intl.org/ resources/code-of-conduct

BSCl. (2009b). Implementation guidelines. Brussels, Belgium: BSCI.

BSCl. (2009c). Management manual. Brussels, Belgium: BSCl.

BSCl. (2009d). Position on wages. Retrived from http://www.bsci-intl.org/ resources/bsci-positions

BSCI. (2009e). Rules and functioning. Retrived from http://www.bsci-intl.org/ resources/rules-functioning

BSCl. (2009f). Social audit guidelines. Brussels, Belgium: BSCl.

BSCI. (2012). Annual report 2011. Retrived from http://www.bsci-intl.org/ resources/annual-report-bsci

Calton, J. M., \& Payne, S. L. (2003). Coping with paradox: Multistakeholder learning dialogue as a pluralist sensemaking process for addressing messy problems. Business and Society, 42(1), 7-42.

Camillus, J. C. (2008). Strategy as a wicked problem. Harvard Business Review, 86(5), 99-106.

Delmas, M. (2001). Stakeholders and competitive advantage. Production and Operations Management, 10(3), 343-358.

Dingwerth, K., \& Pattberg, P. (2006). Global governance as a perspective on world politics. Global Governance, 12(2), 185-203. 
Fama, E. F. (1980). Agency problems and the theory of the firm. The Journal of Political Economy, 88(2), 288-307.

Fama, E. F., \& Jensen, M. C. (1983). Separation of ownership and control. Journal of Law and Economics, 26(2), 301-325.

Fransen, L. W. (2012). Corporate social responsibility and global labor standards: Firms and activists in the making of private regulation. New York, NY: Routledge.

Friese, S. (2012). Qualitative data analysis with Atlas.ti. Thousand Oaks, CA: Sage.

FWF. (2009a). Charter including code of labour practices. Retrived from http://www.fairwear.org/ul/cms/fck-uploaded/documents/companies/ FWFdocs/fwfcharterjanuary2011.pdf

FWF. (2009b). Manual for companies affiliated to fair wear foundation. Retrived from http://www.fairwear.org/ul/cms/fck-uploaded/documents/ companies/ManualsReports/manualaffiliatesoctober2009.pdf.

FWF. (2010). Living wage: FWF policy and practice. Retrived from http://www .fairwear.org/ul/cms/fck-uploaded/documents/policydocs/ fwflivingwagepolicynov2010.pdf

FWF. (2012a). Fair Wear Foundation annual report 2011. Retrived from http: //www.fairwear.org/ul/cms/fck-uploaded/documents/fwfpublications _reports/FWFAnnualReport2011.pdf

FWF. (2012b). FWF audit manual. Retrived from http://www.fairwear.org/ul/ cms/fck-uploaded/documents/policydocs/FWFauditmanual -march2012.pdf

FWF. (2012c). Terms for audits by FWF audit teams. Retrived from http://www .fairwear.org/ul/cms/fck-uploaded/documents/policydocs/ termsforFWFauditsjan2012.pdf

George, A. L., \& Bennett, A. (2005). Case studies and theory development in the social sciences. Cambridge, MA: MIT Press.

Gibbs, G. (2007). Analyzing qualitative data. Thousand Oaks, CA: Sage.

Gläser, J., \& Laudel, G. (2010). Experteninterviews und qualitative Inhaltsanalyse. Wiesbaden, Germany: VS Verlag.

Held, D. (2004). Global covenant. Cambridge, England: Polity Press.

Hill, C. W., \& Jones, T. M. (1992). Stakeholder-agency theory. Journal of Management Studies, 29(2), 131-154.

ILO. (2012). ILOLEX: Database of international labour standards. Retrieved from http://www.ilo.org/ilolex/english/convdisp1.htm

Jensen, M. C., \& Meckling, W. H. (1976). Theory of the firm: Managerial behavior, agency costs and ownership structure. Journal of Financial Economics, 11(4), 305-360.

Levy, D. L., \& Kaplan, R. (2008). Corporate social responsibility and theories of global governance. In A. Crane, A. McWilliams, D. Matten \& J. Moon (Eds.), The Oxford handbook of corporate social responsibility (pp. 432451). Oxford, England: Oxford University Press.

Lijphart, A. (1971). Comparative politics and the comparative method. American Political Science Review, 65, 682-693. 
Mayring, P. (2010). Qualitative inhaltsanalyse: Grundlagen und techniken. Weinheim, Germany: Beltz Verlag.

Mena, S., de Leede, M., Baumann, D., Black, N., Lindeman, S., \& McShane, L. (2010). Advancing the business and human rights agenda: Dialogue, empowerment, and constructive engagement. Journal of Business Ethics, 93, 161-188.

Miles, E. L., Underdal, A., Andresen, S., Wettestad, J., Skjaerseth, J. B., \& Carlin, E. M. (2002). Environmental regime effectiveness: Confronting theory with evidence. Cambridge, MA: MIT Press.

Prahalad, C. K., \& Hamel, G. (1990). The core competence of the corporation. Harvard Business Review, 68(3), 79-91.

Przeworski, A., \& Teune, H. J. (1970). The logic of comparative social inquiry. New York: Wiley \& Sons.

Rieth, L. (2009). Global governance und corporate social responsibility. Opladen: Budrich UniPress.

Rondinelli, D. A. (2002). Transnational corporations: International citizens or new sovereigns? Business and Society Review, 107(4), 391-413.

Rosenau, J. N., \& Czempiel, E.-O. (1992). Governance without government: Order and change in world politics. Cambridge, England: Cambridge University Press.

Sachs, S., \& Rühli, E. (2011). Stakeholders matter: A new paradigm for strategy in society. Cambridge, England: Cambridge University Press.

Shankman, N. A. (1999). Reframing the debate between agency and stakeholder theories of the firm. Journal of Business Ethics, 19, 319-334.

Strand, R. (2010). The stakeholder dashboard. Greenter Management Journal, 54, 23-36.

Van Tulder, R., \& Kolk, A. (2001). Multinationality and corporate ethics: Codes of conduct in the sporting goods industry. Journal of International Business Studies, 32(2), 267-283.

Willke, H. (2014). Demokratie in zeiten der konfusion. Berlin, Germany: Suhrkamp.

Zadek, S. (2004). The path to corporate responsibility. Harvard Business Review, 82(12), 125-132.

Dr. Claude Meier studied Political Science, Business Administration and Indology at the University of Zurich. Since his doctorate (PhD) at the University of Zurich in International Relations, he works as Subject Expert and Associated Head of the Institute for Strategic Management: Stakeholder View at the University of Applied Sciences Zurich (HWZ). He conducts research on Business and Society as well as on Global Governance. claude.meier@fh-hwz.ch

This paper is published under the terms of the AttributionNonCommercial-NoDerivatives 4.0 International (CC BY-NC-ND 4.0) License (http://creativecommons.org/licenses/by-nc-nd/4.0/). 